\title{
A study on the types of dehydration and serum sodium level in infants and young children at the time of hospital admission with acute diarrhea in rural area of Jharkhand
}

\author{
Vishal $^{1}$, Madhurima Prasad ${ }^{2}$ \\ ${ }^{1}$ Dr. Vishal, Specialist Medical Officer, Department of Pediatrics, CHC, Patratu, Jharkhand, ${ }^{2}$ Dr. Madhurima Prasad, \\ Senior Resident, Department of Surgery, RIMS, Ranchi, Jharkhand, India.
}

Corresponding Author: Dr. Madhurima Prasad, Mahalaxmi Nursing Home, Thana Chowk, Ramgarh Cantt, Jharkhand, India. Email: madhurimapd@gmail.com

\begin{abstract}
Objectives: This study was done to know the incidence of different type of dehydration clinically in acute watery diarrhea (mild, moderate and severe) along with serum sodium level (isonatraemic, hyponatraemic, hypernatraemic) at presentation in hospital. Method: Prospective observational study done at admission on children below 5 years of age with acute watery diarrhea. Dehydration was clinically classified as mild, moderate and severe. Serum sodium level was estimated at admission with Roche cobas autoanalyzer (indirect ISE method) and separated into 3 groups: (1) isonatraemic / hyponatraemic/ hypernatraemic dehydration. Children who had dysentery or diarrhea more than 7 days duration, taken iv fluids, metabolic disease/chronic medical condition were excluded from the study. Results: There were 68 patients in which $64.7 \%$ were males. $42.6 \%$ cases were between 1-2 year of age. 45 cases had moderate dehydration in which $57.7 \%$ had isonatraemic dehydration. 23 cases had severe dehydration in which $60.8 \%$ had hyponatraemic dehydration. There was no hypernatraemic dehydrated patients among severe dehydration / appropriate ORS or plain water groups. Only $10(14.7 \%)$ cases were taking appropriate oral rehydration therapy in which $60 \%$ have isonatraemic dehydration. 12 Patients on concentrated ORS had 75\% isonatraemic dehydration. 18 Patients on diluted ORS had 55.5\% isonatraemic dehydration. Conclusion: About two third had moderate dehydration and majority had isonatraemic dehydration. Very few patients were given appropriate ORS therapy. Thus, we need to educate society about proper domiciliary treatment (appropriate fluid/ORS solution) in case of diarrhoea.
\end{abstract}

Key words: Acute diarrhoea, Type of dehydration, sodium level, Oral rehydration therapy, home therapy

\section{Introduction}

Acute diarrhoea is the most common gastrointestinal disorder in children, andthe most direct effect of it is dehydration [1]. It is manifested as sudden episode of loose watery stool which is generally 3 or more episodes per day and last for seven to ten days, generally less than 14 days [2]. most episodes of acute diarrhoea are infectious and caused by a variety of viruses and bacteria [3].

Globally diarrhoea is the $3^{\text {rd }}$ most common cause of under 5 mortality after pneumonia and preterm birth [4] and majority of them occurs in developing countries [5]. India has made steady progress in reducing deaths in children younger than 5 years, with total deaths

Manuscript received: $4^{\text {th }}$ October 2018

Reviewed: $14^{\text {th }}$ October 2018

Author Corrected: $19^{\text {th }}$ October 2018

Accepted for Publication: $22^{\text {nd }}$ October 2018 declining from 2.5 million in 2001 to 1.5 million in 2012 [6] but the proportional mortality due to diarrhoea is still very high. About $80 \%$ of deaths due to diarrhoea occur in the first 2 years of life in which main cause is dehydration and dyselectrolytemia. World wide only $20 \%$ of children with acute diarrhoea receive appropriate Oral rehydration therapy [7]. Sodium is a major osmotic determinant of ECF. Serum sodium level in a dehydrated patient may be normal, low or high. On the basis of serum sodium level, dehydration is classified as [8]:

(i) Isonatremic (Serum sodium level 130 to 150 $\mathrm{meq} / \mathrm{L})$

(ii) Hyponatremic dehydration (serum sodium level below130 meq/L)

(iii) Hypernatremic dehydration (serum sodium level $>150 \mathrm{mEq} / \mathrm{L}$ ) 
According to severity, dehydration is classified as Mild (thirsty, restless, $4-5 \%$ less body weight);

Moderate (dry mucosa, absent tear, sunken eye ball and fontanel, thready pulse, dark urine with reduced amount, skin pinch retracts slowly $<2.0$ sec., $6-9 \%$ loss of body weight)

Severe (drowsy, cold extremities, impalpable pulse, deep and rapid respiration, very sunken fontanel systolic BP $<90 \mathrm{~mm}$ of $\mathrm{Hg}$ or unrecordable, skin pinch retraction time $>2.0 \mathrm{sec}$, grossly sunken eyeball, parchment like mucous membrane, urine flow absent for several hour, more than $10 \%$ loss of body weight).

Each type of dehydration requires appropriate modification in therapeutic approach according to severity and serum sodium level. Considering the huge magnitude of the problem this study was taken to analyze dehydration and electrolyte changes during episode of diarrhoea so that we can come up with appropriate treatment modification in our setup.

The present study has been undertaken with following aims and objectives:

(1) to know the incidence of different type of dehydration (mild, moderate and severe) clinically in acute watery diarrhea at presentation in our hospital up to 5 years of age

(2) to study about the incidence of different types of dehydration (isonatraemic, hyponatraemic, hypernatraemic) on the basis of serum sodium level

(3) to study the change in serum sodium level according to change in severity of dehydration.

\section{Material and Methods}

Place of study: Indoor patients of Department of Pediatrics, community health centre, Patratu, Jharkhand.

Type of study: cross-sectional observational study.

\section{Original Research Article}

Sampling method: All cases were selected for 3 months from March 2018 to May 2018. 84 cases were selected and followed up.16 patients were lost to follow-up and 68 cases were followed up for the analysis.

Sample collection: $5 \mathrm{ml}$ of venous blood was collected from median cubital vein by trained lab technician under sterile conditions using a disposable syringe at admission and after treatment. Serum sodium was measured using automated electrolytes analyser (Rochecobas autoanalyzer) using indirect ISE method.

Inclusion Criterion: a. All children aged 0-5 years of age, of either sex having history of acute onset of watery diarrhoea not more than 7 days of duration.
b. All cases must have dehydration.

\section{Exclusion Criterion}

a. Patients who had dysentery

b. diarrhea more than 7 days duration

c. Patient who had taken treatment somewhere else / taken iv fluids

d. Patients with metabolic disease/chronic medical condition which has propensity to alter serum electrolytes like nephrotic syndrome, renal failure and

e. Patients who did not cooperate and did not come for follow up.

Statistical Method: Simple statistical descriptive measures primarily focusing on measures of central tendency. The study was carried out with the written approval of the parents. Detailed history and thorough clinical examination of cases included in the study was done. Along with general information and presenting illness special emphasis was given to type of fluid, diet taken prior to admission. General physical examination done and type of dehydration assessed clinically.

\section{Result}

Table-1: Sex distribution of the study population

\begin{tabular}{|c|c|c|c|}
\hline & Boy & Girls & Total \\
\hline$<1$ year & 13 & 8 & $21(30.8 \%)$ \\
\hline $1-2$ years & 20 & 9 & $29(42.6 \%)$ \\
\hline $2-5$ years & 11 & 7 & $18(26.4 \%)$ \\
\hline & $\mathbf{4 4}(\mathbf{6 4 . 7} \%)$ & $\mathbf{2 4}(\mathbf{3 5 . 2} \%)$ & $\mathbf{6 8}$ \\
\hline
\end{tabular}

Number of boys were more than girls and maximum number of cases are from 1-2 years of age 
Table-2: Types of dehydration.

\begin{tabular}{|c|c|c|c|c|}
\hline Severity of dehydration & No.of cases & \multicolumn{3}{|c|}{ Type of dehydration } \\
\hline No & 0 & Isonatraemic & Hyponatraemic & Hypernatraemic \\
\hline Moderate dehydration & $45(66.1 \%)$ & $26(57.7 \%)$ & $16(35.5 \%)$ & $3(6.6 \%)$ \\
\hline Severe dehydration & $23(33.8 \%)$ & $9(39.1 \%)$ & $14(60.8 \%)$ & 0 \\
\hline
\end{tabular}

In moderate dehydration maximum cases are of isonatraemic type while in severe dehydration maximum cases were of hyponatraemic type. There were no hypernatraemic dehydration among severe dehydration group

Table-3: Different type of fluid taken prior to admission and type of dehydration in them.

\begin{tabular}{|c|c|c|c|c|c|}
\hline $\begin{array}{c}\text { Type of fluid taken } \\
\text { prior to admission }\end{array}$ & No fluid & $\begin{array}{c}\text { Adequately } \\
\text { diluted ORS }\end{array}$ & $\begin{array}{c}\text { Highly diluted } \\
\text { ORS/low } \\
\text { sodium fluid }\end{array}$ & $\begin{array}{c}\text { Highly concentrated } \\
\text { ORS/high sodium } \\
\text { fluid }\end{array}$ & $\begin{array}{c}\text { Salt free } \\
\text { fluid/plain } \\
\text { water }\end{array}$ \\
\hline Number of cases & $18(26.4 \%)$ & $10(14.7 \%)$ & $18(26.4 \%)$ & $12(17.6 \%)$ & $10(14.7 \%)$ \\
\hline $\begin{array}{c}\text { Isonatraemic } \\
\text { dehydration }\end{array}$ & 8 & 6 & 10 & 9 & 2 \\
\hline $\begin{array}{c}\text { hyponatraemic } \\
\text { dehydration }\end{array}$ & 9 & 4 & 7 & 2 & 8 \\
\hline $\begin{array}{c}\text { hypernatraemic } \\
\text { dehydration }\end{array}$ & 1 & 0 & 1 & 1 & 0 \\
\hline
\end{tabular}

Only $14.7 \%$ cases were given adequately diluted ORS.

\section{Discussion}

This observatory study was done to know the incidence of different type of dehydration clinically in acute watery diarrhoea and change in serum sodium level with it. Special emphasis has been given to find out the incidence of different types (isonatraemic, hyponatraemic, and hypernatraemic) of dehydration and their correlation with clinical presentation.

Maximum number of cases were from 1-2 years of age. this is in accordance with the observation made by Naruka et al [9]. He observed 51\% during first 2 years of life and $27.5 \%$ between 1 to 4 years of age. Mittal et al [10], in their study, observed $90 \%$ cases below 3 years of age.

This may be due to poor hygiene, and improper handling and storage of milk and other food material, as well as immaturity of immune system of the body rendering it susceptible to microbial infection. Children frequently Infants and preschool children had a comparatively lower incidence.

Males (64.7\%, $\mathrm{n}=44)$ outnumbered female child $(35.2 \%, n=24)$. This disparity in sex may be explained by the fact that parents are more concerned about the male child. Similar incidence was found by Naruka et al [9]. Almost all cases were dehydrated at the time of presentation in hospital. About $66.1 \%, \mathrm{n}=45$ cases were moderately dehydrated and $33.8 \%, \mathrm{n}=23$ of children were severely dehydrated. The reason for the high incidence of dehydration may be due to delay in starting treatment and bringing the child to hospital, very poor knowledge of dehydration therapy.

Depending upon serum sodium content at the time of admission, 51.4\%, $\mathrm{n}=35$ were isonatraemic, $44.1 \%$, $\mathrm{n}=30$ were hyponatraemic and only $4.4 \%, \mathrm{n}=3$ were hypernatraemic. Darel et al [11] in their study found isonatraemic dehydration in $79.1 \%$, Hyponatraemic in $12.3 \%$ and hypernatraemic in $8.6 \%$. Hirschorn N [12], and Kumar V et al [13]in their study found isonatraemic dehydration as the most common type of dehydration in tropics.

Isonatraemic dehydration was present in majority of patient which may be due to lower stool electrolyte losses in early infancy [14] and initiation of ORS prior to hospitalization. Hyponatraemic dehydration was observed in $44.1 \%$ which may be due to intake of low salt containing diet $[15,12]$ during diarrhoea and intake of large quality of plain water and its retention due to increased secretion of Antidiuretic hormone (ADH) in hypovoluemic condition [16], Inadequate and prolonged breast feeding which supplies about $1 / 4$ amount of 
sodium than cow's or very diluted cow's milk $[17,18]$, excess loss of electrolytes in sweat in very hot climate [17]. In our study there is higher incidence of hyponatraemia in severely dehydrated patients $(60.8 \%)$ than in moderately dehydrated patients $(35.5 \%)$.

Mittal et al [10] were of the opinion that mean serum sodium level gradually decreased as the severity of dehydration increased. However, Purohit and Jyotsana [19] reported earlier that there was no relation between the severity of dehydration and hyponatraemia.

The incidence of hyponatraemia was highest in patients who have taken plain water $(80 \%)$ prior to hospitalization followed by those have taken low sodium ORS (38.8\%), high sodium ORS (16.6\%) or no/ very less amount of fluid (50\%). High incidence of hyponatraemia with intake of plain water was reported by Hirschhorn [12], and many other workers.

This may be due to retention of water as a result of increased secretion of $\mathrm{ADH}$ in hypovolumeic condition [16]. Aperia A et al [20] found mild transient hyponatraemia in infants and toddlers who received low sodium ORS. On the contrary Herzog et al [21] found incidence of hyponatraemia in low sodium ORS is approximately $6.1 \%$. No cases of hypernatraemic type of dehydration in this group were found in severe dehydration.

In summary, Following are observed during the study-

1. Maximum number of cases was in the age group of 1 - 2 years with predominant male patients. About two third of cases have moderate dehydration and rest have severe type of dehydration.

2. Isonatraemic dehydration was the most common type of dehydration $(51.40 \%)$ followed by hyponatraemic dehydration $(44.11 \%)$ and hypernatraemic dehydration $(4.4 \%)$ was least common.

3. Isonatraemic dehydration was the predominant type $(57.7 \%)$ in moderate dehydration whereas hyponatraemic dehydration was more common $(60.8 \%)$ in severe dehydration. Hypernatraemic dehydration was only seen in moderate dehydration (6.6\%).

4. Isonatraemic dehydration was the most common type of dehydration observed in cases who have received high/low sodium containing ORS prior to hospitalization whereas hyponatraemic dehydration was more common in children who received plain water during diarrhea prior to hospital admission

\section{Conclusion}

Thus, this study concludes that incidence of diarrhoea is higheramong children between 1-2 years of age so proper hygienic weaning method is important to decrease the incidence. About $1 / 3^{\text {rd }}$ cases were of severe dehydration thus children should be brought to hospital early as they get dehydrated very rapidly.

Only $14.7 \%$ of patients were given adequate ORS so parents need at least proper domiciliary management training. Many a times Hypernatraemic dehydration got missed as classical features of dehydration are often absent in them, so primary care providers should evaluate every child very carefully.

Acknowledgement: I am thankful to my co-author, Dr. Madhurima Prasad for research, guiding and supporting me for the preparation of this article. We are also thankful for the patients who participated in the study

What this study adds: Majority of patients were not given adequate domiciliary fluid. 30 out of 40 patients (75\%) who were given ORS were not adequately made so there was much variation of serum sodium levels, this reflects huge gap of knowledge among common people.

So concrete steps should be taken to educate them about proper ORS preparation method, only providing them ORS packet is not enough.

Abbreviation: ORS oral rehydration solution, ORT oral rehydration therapy, ECF extracellular fluid, ADH antidiuretic hormone, ISE ion sensing electrodes.

Funding: Nil, Conflict of interest: None initiated, Perission from IRB: Yes

\section{References}

1. Radlović N, Leković Z, Vuletić B, et al. Acute Diarrhea in Children. SrpArhCelokLek. 2015 Nov-Dec; 143 (11-12): 755-62.

2. Riddle MS, Du Pont HL, Connor BA. ACG Clinical Guideline: Diagnosis, Treatment, and Prevention of Acute Diarrheal Infections in Adults. Am J Gastroenterol. 2016 May;111(5):602-22. doi: 10.1038/ ajg. 2016. 126. Epub 2016 Apr 12.

3. Abdullah $\mathrm{H}$ Baqui,TahmeedAhmed,Diarrhoea and malnutrition in childrenReplacing fluid and minerals, particularly zinc, remains vitalBMJ. 2006 Feb 18; 332 (7538): 378.doi:10.1136/bmj.332.7538.378 
4. Million Death Study Collaborators, Bassani DG, Kumar R, et al. Causes of neonatal and child mortality in India: a nationally representative mortality survey. Lancet. 2010 Nov 27;376(9755):1853-60. doi: 10.1016/ S0140-6736(10)61461-4. Epub 2010 Nov 12.

5. Kosek M, Bern C, Guerrant RL. The global burden of diarrhoeal disease, as estimated from studies published between 1992 and 2000. Bull World Health Organ. 2003; 81 (3):197-204. Epub 2003 May 16.

6. Bhan MK. Accelerated progress to reduce under-5 mortality in India. Lancet Glob Health. 2013 Oct; 1(4): e172-3. doi: 10.1016/S2214-109X(13)70076-7. Epub 2013 Sep 19.

7. Jones G, Steketee RW, Black RE, et al. How many child deaths can we prevent this year? Lancet. $2003 \mathrm{Jul}$ 5; 362 (9377): 65-71. DOI: 10.1016/S0140-6736(03) 13811-1

8. Karen S.Powers. Dehydration: Isonatremic, Hyponatremic, and Hypernatremic Recognition and Management. Pediatrics in Review Jul 2015, 36 (7) 274285; DOI: 10.1542/pir.36-7-274

9. Naruka BS, Sharma U, Saxena S. A clinical profile of diarrhoea in infancy and childhood. A study of 200 cases. Indian J Pediatr. 1974 Dec;41(323):374-83.

10. Mittal, S. K.; Saxena, S.; Mundkur, N.; Srivastava, G.; Gupta, S.Acute diarrhea inmalnourished children. Clinical, biochemical and bacteriological profile. Indian Pediatrics 1980; 17(3): 247-254.

11. DaralTS, Singh HP, Sachdev HP, Mohan M, Mathur M And Bhargava SK. acute dehydrating diarrhoea. clinical profile in neonates and young infants. Indianpediatrics. $1985 ; 22: 333-338$.

12. Hirschhorn N. The treatment of acute diarrhea in children. An historical and physiological perspective.
Am J Clin Nutr. 1980 Mar;33(3):637-63. DOI:10.1093/ ajen/33.3.637

13. Kumar V, Datta N, Wadhwa SS, Singhi S. Morbidity and mortality in diarrhea in rural Haryana. Indian J Pediatr. 1985 Sep-Oct;52(418):455-61.

14. Bhargava SK, Sachdev HPS, Das Gupta B et al. oral rehydration of neonates and young infants with dehydrating diarrhoea: comparison of low and standard sodium content in oral rehydration solutions. J. pediatr. gastroenterol nutr. 1984; 3:500-505.

15. Achar ST And Athreya BH. observations on some aspects of parenteral fluid therapy in infantile gastroenteritis in India. Indian pediatr. 1964; 1:309-318.

16. Ewe K., Karbach U. (1989) Functions of the Alimentary Canal. In: Schmidt R.F., Thews G. (eds) Human Physiology. Springer, Berlin, Heidelbergdoi. https://doi.org/10.1007/978-3-642-73831-9_29

17. Udani PM, Shah PM, Mukerji S, et al. Trends in the treatment of acute diarrhoeas in infancy. Indian Pediatr. 1968 Jan;5(1):1-16.

18. Kingston ME. Biochemical disturbances in breastfed infants with gastroenteritis and dehydration. J Pediatr. 1973 Jun;82(6):1073-81.

19. Purohit KR, Jyotsna PS. Electrolyte disturbances in acute diarrhoea. Indian J Pediatr. 1971 Oct;38(285): 393-5

20. Aperia A, Marin L, Zetterström R, et al. Salt and water homeostasis during oral rehydration therapy. $\mathrm{J}$ Pediatr. 1983 Sep;103(3):364-9.

21. Herzog LW, Bithoney WG, Grand RJ. High sodium rehydration solutions in well-nourished outpatients. Acta Paediatr Scand. 1987 Mar;76(2):306-10.

\section{How to cite this article?}

Vishal, Madhurima Prasad. A study on the types of dehydration and serum sodium level in infants and young children at the time of hospital admission with acute diarrhea in rural area of Jharkhand. Int J Pediatr Res. 2018;5(10):506-510. doi:10.17511/ijpr.2018.i10.05. 